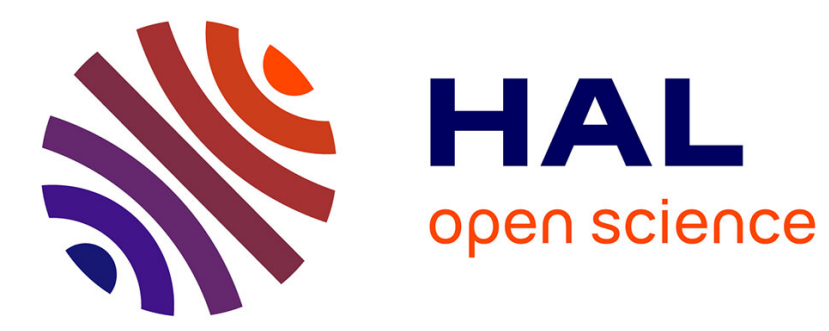

\title{
Penser les dynamiques politiques des musiques populaires : communalisations, affects et tactiques populaires
}

\author{
Jedediah Sklower
}

\section{To cite this version:}

Jedediah Sklower. Penser les dynamiques politiques des musiques populaires: communalisations, affects et tactiques populaires. Elsa Grassy; Jedediah Sklower. Politiques des musiques populaires au XXIe siècle, Mélanie Seteun, pp.9-38, 2016, Musique et Société, 978-2-913169-39-5. 10.4000/books.ms. 890 . hal-02183426

\section{HAL Id: hal-02183426 \\ https://hal.science/hal-02183426}

Submitted on 15 Jul 2019

HAL is a multi-disciplinary open access archive for the deposit and dissemination of scientific research documents, whether they are published or not. The documents may come from teaching and research institutions in France or abroad, or from public or private research centers.
L'archive ouverte pluridisciplinaire HAL, est destinée au dépôt et à la diffusion de documents scientifiques de niveau recherche, publiés ou non, émanant des établissements d'enseignement et de recherche français ou étrangers, des laboratoires publics ou privés. 


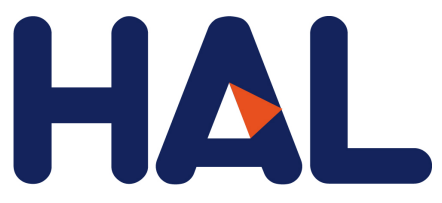

archives-ouvertes

\title{
Penser les dynamiques politiques des musiques populaires : communalisations, affects et tactiques populaires
}

\author{
Jedediah Sklower
}

\section{- To cite this version:}

Jedediah Sklower. Penser les dynamiques politiques des musiques populaires: communalisations, affects et tactiques populaires. Politiques des musiques populaires au XXIe siècle, Mélanie Seteun, pp.9-38, 2016, 978-2-913169-39-5. hal-02183426

\section{HAL Id: hal-02183426 \\ https://hal.archives-ouvertes.fr/hal-02183426}

Submitted on 15 Jul 2019

HAL is a multi-disciplinary open access archive for the deposit and dissemination of scientific research documents, whether they are published or not. The documents may come from teaching and research institutions in France or abroad, or from public or private research centers.
L'archive ouverte pluridisciplinaire HAL, est destinée au dépôt et à la diffusion de documents scientifiques de niveau recherche, publiés ou non, émanant des établissements d'enseignement et de recherche français ou étrangers, des laboratoires publics ou privés. 


\section{Penser les dynamiques politiques \\ des musiques populaires: communalisations, affects et tactiques populaires}

Jedediah Sklower

Toute réaction à la musique est sympathique à un ordre social' .

Theodore Gracyk, 2007 : 167

Car la question n'a jamais été pour les dominés de prendre conscience des mécanismes de la domination, mais de se faire un corps voué à autre chose qu'à la domination.

Jacques Rancière, 2009 : 69

\section{Misérabilisme, communion, médiations}

L'avènement $^{2}$ de la culture de masse a inauguré une nouvelle ère dans le soupçon des élites à l'encontre du peuple et de sa culture. Celui-ci ne date pas du xix siècle, mais la conjonction du mouvement de démocratisation de la vie politique et de massification de la production culturelle par de nouvelles industries a constitué un défi inédit à l'ordre de la culture légitime et à son projet politique.

1. Toutes les traductions de citations originales anglaises sont de l'auteur.

2. Pour leurs précieuses lectures critiques de ce texte, I'auteur tient à remercier Eric Drott, Elsa Grassy et Michael Spanu. 
Des discours analogues sont venus condamner les effets supposés délétères des différentes déclinaisons marchandes des arts, des loisirs et de l'information - de la presse populaire et des « romans à quatre sous » de la seconde moitié du xix siècle jusqu'aux jeux vidéos aujourd'hui, en passant par les différents masques de la « musique du diable », le cinéma, la télévision ou les comic books. Le peuple était détourné des œuvres et des institutions édifiantes. Devenu masse criminelle dans les premiers travaux de psychologie des foules (Mattelart, 2011 : 273-281), il trouvait même dans cette culture un catalyseur, menaçant d'organiser le passionnel, de rationaliser et d'intensifier le rythme de ses révoltes contre les autorités légitimes. C'était un amplificateur désastreux de l'irrationalité de ses destinataires.

Dans la lignée du projet émancipateur des Lumières, la critique progressiste s'en prit à ces phénomènes à partir d'un postulat égalitaire : en tant que reflet des intérêts des détenteurs de ses moyens de production, comment cette culture industrialisée pouvait-elle contribuer à autre chose qu'à maintenir le peuple dans l'ignorance et la soumission? Discours et formes en appelant au plus petit dénominateur commun et nourrissant les passions, la culture de masse était le nouvel instrument de l'enfermement de l'homme dans l'état de minorité. Elle n'était alors plus que renforcement de la domination à l'ère démocratique, narcotique interrompant le progrès de l'émancipation humaine.

Souligner - brièvement ${ }^{3}$ - les analogies entre ces deux facettes décadente et progressiste du misérabilisme culturel ne signifie évidemment pas pour nous les renvoyer dos à dos. Pour ne parler que des représentants les plus éminents du second versant, l'œuvre d'Adorno est la première à tenter de penser ensemble les structures et pratiques de production, les formes et leur réception. Qu'on lui oppose, ici, l'indépendance relative des champs de production et de réception (Bourdieu, 1979 : 255-258), là, une conception pragmatique des médiations musicales (Hennion, 2007 : 94-105), ou

3. Cette introduction, déjà longue, ne pouvait pas être le lieu d'une critique approfondie du misérabilisme, entreprise ailleurs et bien mieux que nous ne saurions le faire (voir Grignon \& Passeron, 1989). Pour une défense esthétique des musiques populaires, voir notamment Shusterman, 1992; Gracyk, 2007. 
encore sa méconnaissance des musiques dont il parlait, l'originalité de son approche holiste et systémique de " l'industrie culturelle » (Adorno \& Horkheimer, 1983), de la « musique légère » (Adorno, 1991 ; 2001) et du jazz (1986) à l'ère contemporaine, combinant économie politique, esthétique et sociologie, fut décisive pour poser les premiers jalons d'une analyse scientifique de l'objet qui nous intéresse ici - les musiques populaires. De même, bien qu'elle se soit refusée à penser les médiations de l'expérience esthétique, la sociologie de l'art et des pratiques culturelles de Bourdieu est fondamentale pour aborder les stratégies des artistes, les discours et la mécanique des attachements de nombre d'amateurs - nous enfonçons des portes ouvertes.

Il faut également dire un mot des optimistes. Comme l'écrit JeanPierre Rioux, au tournant du xx siècle, "la masse a séduit et inquiété à la fois dès qu'elle s'est mise à consommer des médiations et des productions de tous ordres, culturelles comprises » (Rioux et Sirinelli, 2005 : 70). Une autre tradition de recherche sur la culture et la communication à l'ère de la reproductibilité technique fut lancée à la fin du xIx siècle. Peu après les travaux de Scipio Sighele et Gustave Le Bon, Gabriel Tarde se prit de curiosité pour les nouveaux moyens de communication de l'époque et opposa à leurs foules l'alternative positive du public (Mattelart, 2011 : 281-287). Les philosophes de l'École de Chicago allaient reprendre ses intuitions et penser un usage démocratique des médias, dans le sillage de John Dewey et de ce que James Carey a appelé sa « vision rituelle de la communication » (2009: 44). Médias et industries culturelles contribuèrent à une certaine homogénéisation de la culture populaire. Ils provoquèrent certes des ruptures dans la transmission culturelle, et purent amplifier le déracinement à l'ère des révolutions industrielles et des migrations internes. Mais dans la mesure où la politisation des classes populaires reposait sur la constitution d'identités (sociales, culturelles, nationales, etc.) et de mythologies collectives débordant et reconfigurant les cadres antérieurs - la communication comme « communion » (ibid.) -, on peut considérer que ce mouvement fut un prélude nécessaire (sans pour autant être suffisant) à l'accès effectif des masses à la représentation politique. Culture et médias de masse furent des rouages de la formation d'une opinion publique, d'une dynamique d'unification subjective de divers pans des classes 
populaires : "Les Barbares ont investi la vie politique, la vie économique et la vie culturelle elle-même, à coups de suffrage universel, de travail salarié, d'associations et de canards à un sou » écrit encore ironiquement Jean-Pierre Rioux (Rioux \& Sirinelli, 2005 : 74).

Comment penser la puissance politique de ces formes contradictoires? Les musiques populaires sont tributaires d'une industrie et de moyens de stockage et de reproduction mécanique pour être produites et diffusées ${ }^{4}$, ainsi que des nombreuses médiations matérielles et symboliques qui participent de leur production, de leur création et de leur réception - discours, dispositions, dispositifs techniques, lieux, mises en scène... Penser leurs formes, leurs significations et leurs effets suppose d'accepter pleinement ce préalable : elles sont façonnées par une hétéronomie foisonnante, plus intense, peut-être - il faudrait en débattre -, que les musiques savantes ou traditionnelles. Le musicien, le groupe, le DJ composent avec une série de contraintes et d'intermédiaires, leur travail fait des détours par des traductions multiples qui leur échappent. L'analyse de la production, de la signification et des usages des musiques populaires ne saurait s'abstraire de celle de leurs conditions d'avènement. Elle ne peut alors ni emprunter les chemins romantiques des figures du génie autonome ou de l'émanation incarnée du peuple, ni ceux, "populistes », de I'émancipation constante dans la réception. Car au-delà de cette reconnaissance de dette vis-à-vis de postulats classiques de l'histoire sociale de l'art et de la théorie de la médiation, l'idée que nous souhaitons défendre ici est que les musiques populaires - dans I'ensemble de leurs pratiques - expriment, comme l'écrivent Dario Rudy et Yves Citton, un "désir d'épaissir la médiation » et résistent à " cet idéal de perfection, de transparence [...] d'immédiateté et d'immédiation » (Rudy \& Citton, 2014 : 110, 114). Elles jouent avec leurs médiations, les exagèrent, voire les mettent en abyme. Jusque dans leurs maladroites tentatives de camouflage idéaliste ou dans leurs mises en scène kitsches d'une symbiose communautaire. Cela ne veut pas pour autant dire que toute analyse esthétique de ces musiques soit proscrite, ou que l'examen des rapports entre ces

4. Une définition « classique » (voir Tagg, 1982), quoique contestée (Scott, 2008), des musiques populaires, à laquelle nous souscrirons ici. 
formes et les questions d'identité serait forcé d'emprunter le registre de la démystification d'une mascarade. Cela revient simplement à reconnaître d'une part que, pour comprendre ce que sont ces musiques d'un point de vue formel, il faut prendre en compte ce que leur fait leur nature industrielle, principalement le rôle des structures de production et des outils phonographiques (amplification, enregistrement), ainsi que - dans une perspective pragmatique celui du feedback des usages et du monde social (Hennion, 2013). D'autre part, pour analyser ceux-ci et leur signification sociale, il faut de même partir du continuum des imbrications précédentes. Le dispositif musical est l'envers, " côté » production, des médiacultures (Maigret \& Macé, 2005) « côté » réception : toutes deux appellent des médiations pour advenir. Il faut dépasser le face-à-face pour penser les circulations entre les deux pôles, les coproductions du façonnement des formes et de l'expérience esthétique.

La tare commune des analyses pessimistes et optimistes, misérabilistes et populistes, portant sur la valeur des formes, des significations et des modalités de réception qu'on en déduit hypothétiquement, est leur manière de " dépeupler » les musiques populaires de ces médiations (Hennion, 2007 : 106 sqq.). Gravées en leurs formes réifiées, il n'y aurait que l'empreinte de l'industrie, déterminant des écoutes passives, fétichistes. Ou bien tatoué sur le corps des dominés, l'habitus quasi indélébile contraindrait les amateurs à n'en faire des expériences originales que par miracle ou apostasie sociale. Les circulations sont interrompues par la focalisation sur une instance, détentrice originelle de toutes les déterminations : tantôt les machinations du capitalisme omnipotent, tantôt l'aliénation quasiment inébranlable des dominés. Inversement, dans les consommations ordinaires se nicheraient des tactiques subversives porteuses d'une irréductible puissance populaire. Les analyses qui extraient les musiques populaires de leur situation dans un environnement économique, sociopolitique et culturel - qui les détachent de "leurs» mondes (Becker, 1988) et « du » monde - se réduisent souvent à une herméneutique abstraite confinant à l'idéologie, qu'elle soit démystificatrice ou empathique.

Si l'on ne peut assigner exclusivement la culture populaire et les produits des industries culturelles à leurs déterminations socioéconomiques, ils n'échappent pas pour autant « au champ de forces des 
relations de pouvoir et de domination culturels » (Hall, $2007: 72$ ). C'est dès lors précisément dans ces méandres qu'il faut aller dénicher la possibilité et la spécificité de leurs politiques. En tant qu'elles composent avec les contraintes du monde social, les musiques populaires offrent ces plaisirs "vulgaires » et s'ouvrent à des identifications hétérodoxes encourageant l'adhésion et la participation. Elles peuvent ainsi tracer le chemin d'une politique. II n'y a alors pas à rêver une assomption hors de l'emprise de l'hétéronomie, ni une résurrection du mythe perdu d'une culture « du peuple, par le peuple, pour le peuple » : "l'axe du conflit passe au sein même de la culture de masse » (Macé, $2006: 52$ ).

\section{Des possibilités et non une essence}

Dans cet ouvrage, il ne s'agit donc pas de prendre définitivement parti. On croisera, au fil des textes et des différents auteurs, des analyses plus ou moins optimistes, des réussites comme des échecs, des exemples d'engagements aux deux pôles du spectre politique. Avec cette introduction, nous souhaitons simplement dénicher des possibilités, ce que les musiques populaires offrent comme ressources à des formes de mobilisation politique ${ }^{5}$. II s'agit de nuancer le tableau plutôt que de décréter des absolus : non pas nier les puissantes contraintes qui pèsent sur la culture populaire, mais simplement ne pas la condamner à y être soumise définitivement et en toutes circonstances. II faut penser les embranchements possibles, plutôt que des assignations définitives. Nous devons garder à l'esprit qu'il peut y avoir politique, toujours à certaines conditions, le plus souvent de façon ambiguë et précaire, sans garantie de résultats.

Commençons donc d'abord par quelques précautions. D'abord, révéler des formes d'activité à l'œuvre dans les pratiques des musiques populaires, ce n'est pas se contenter de les repérer exclusivement dans les configurations qui complaisent à une définition elle-même idéologiquement située de l'émancipation. II y a bien sûr des formes d'activité qui n'y mènent en rien - c'est la critique de l' « escapism », le refuge

5. Nous n'y traiterons pas des autres acceptions du concept de politique, notamment la musique comme arme au service de pouvoirs répressifs, ou encore les politiques culturelles. 
hors de la réalité (Garnham, 1995 : 69). Un plaisir pris dans telle ou telle activité de réception et/ou un décodage textuel « négocié » ou « oppositionnel » (Hall, 1994) ne constituent pas en soi une politique. Nombreux sont ceux qui conditionnent classiquement la politisation de la culture populaire à l'action mobilisatrice et aux cadrages d'avant-gardes militantes. C'est le cas par exemple de I'historien Michael Denning ${ }^{6}$ dans son travail sur le « front culturel » américain des années 1930, avec son association, pour ce qui est de la musique, de folk, de blues, de jazz hot et de théâtre musical :

L'expérience subalterne ne génère pas nécessairement une critique sociale et une résistance culturelle; la possibilité d'interprétations populaires politisées des marchandises culturelles dépend de la formation [cultivation], de l'organisation et de la mobilisation de publics par des subcultures et des mouvements sociaux contestataires. (2010 : 64)

À ces positions, on pourra néanmoins rétorquer avec Lawrence Grossberg qu'une activité populaire anodine peut être le prélude à une politisation :

Les cultural studies ne partent pas du principe que s'opposer, résister, lutter et survivre (surmonter), ce soit la même chose. Elles soutiennent en revanche que la possibilité d'accomplir les deux premières actions dépend de la réalisation complexe des deux dernières. (1995: 75)

On pourrait rajouter avec Jacques Rancière qu'il s'agit pour les dominés de faire l'expérience de dissensus sensoriels plutôt que de se libérer à I'aide de vérités politiques révélées par une minorité éclairée, non pas "d'acquérir une connaissance de la situation mais des "passions" qui soient inappropriées à cette situation » (2008: 69) - des propos que nous développerons plus bas sur le rôle des affects dans les musiques populaires. L'infrapolitique est de même pour James C. Scott une condition préalable et nécessaire à toute action politique institutionnalisée (1992 : 201). Il faut selon nous penser ensemble émancipation et politisation, ce qui passe par le tissage de liens entre l'expérience populaire prépolitique et le façonnement de pratiques militantes.

6. II étudia sous la férule de Stuart Hall et est l'un des passeurs des travaux du CCCS de Birmingham aux États-Unis. 
Ensuite, de nombreuses formes d'activité soudent des communautés fondées autour d'un projet politique contraire à l'idéal d'émancipation qui sous-tend les recherches des cultural studies ou le paradigme des usages : leurs armes théoriques peuvent tout à fait être reprises dans des analyses valorisant des subcultures ou des contre-cultures non conformes ${ }^{7}$ - l'argument appelant par ailleurs une critique axiologique dudit idéal. De la même manière, dans les manifestations de "résistance rituelle » des dominés, " ruses » (de Certeau, 1990), jeux de " signifyin" » (Gates, 1988) ou " textes cachés » (Scott, 1992) n'ont pas pour essence d'être systématiquement adressés aux oppresseurs identifiés par les universitaires de (telle ou telle) gauche ${ }^{8}$. L'ennemi désigné par une communauté politique n'est pas toujours le bon. Mais c'est là aussi une critique admise par de nombreuses recherches sur la culture populaire. II n'y a pas de ce point de vue d'angélisme, et ce, dès les travaux canoniques du CCCS sur les subcultures (Hall \& Jefferson, 1980; Hebdige, 2008).

De la même manière, définir les formes de communalisation nourries par les musiques populaires comme rapports sociaux, c'est tout autant y déceler les dynamiques de violence et d'oppression qui s'y inscrivent vis-à-vis de dominés et/ou de minorités. Par ailleurs, ces musiques se prêtent tout aussi bien à des usages violents (Johnson \& Cloonan, 2009; Fast \& Pegley, 2012), répressifs (Volcler, 2011) ou militaires (Pieslak, 2009; Cusick, 2006; 20149). Mais encore une fois, cette attention portée aux conflits au sein des subcultures est au cœur du projet des cultural studies et des popular music studies, dont les travaux sérieux ne célèbrent pas aussi hâtivement les noces entre culture populaire et politique.

Ensuite, la défense des "politiques de l'identité » par les cultural studies se teinte de provocation, lorsqu'elle s'adresse tout autant à la gauche " puritaine »(Grossberg, 2015 : 74) qu'à d'autres

7. Cf. la contribution de Di Nunzio et Toscano dans cet ouvrage.

8. Il faudrait à ce sujet décrypter le code gestuel et les jeux de signifyin' d'un Dieudonné ainsi que leur résonance sociale. Ne pourrait-on pas dire, en utilisant les hypothèses de Lhamon (2008) contre nous-mêmes, qu'il aurait toute sa place dans une version française de l'histoire qu'il raconte, le quartier de la Goutte-d'Or remplaçant le marché de Sainte-Catherine?

9. Cf., a contrario, les analyses de Lisa Gilman (2013) sur les usages " doux » des musiques populaires par les soldats américains au front. 
ennemis. Les querelles autour de l'interprétation de la culture populaire et les critiques de la démystification typique de discours matérialistes classiques alimentent dans une certaine mesure une guerre civile intellectuelle au sein de la gauche universitaire (Rancière contre Bourdieu ${ }^{10}$ ou Debord, cultural studies contre théorie critique classique, pragmatisme contre déterminisme...), contribuant pour certains à l'affaiblissement du rôle politique de la recherche, se réduisant pour d'autres à de vains enjeux territoriaux de distinction polémique ${ }^{11}$. La mise en valeur de la polysémie des formes d'activité populaire est nécessaire, mais souffre parfois comme nous I'avons dit d'un optimisme tendanciellement populiste. Surtout, lorsque l'analyse se réduit à une sémiologie interne des phénomènes observés, elle substitue aux usages et effets concrets une signification et une performativité postulées - si ce n'est souhaitées - par l'auteur, qu'il s'agisse des œuvres ou des usages traités comme des signes, sans interrogation sur les contributions de ces " textes » et de leurs décodages à une dynamique de transformation socioculturelle ${ }^{12}$. Or, lorsqu'il s'agit de formes culturelles ambivalentes, dès lors que l'on rompt avec le principe de l'efficacité communicationnelle - l'homogénéité de la signification des textes et de leurs décodages - on ne peut pas, en l'absence de matériau empirique sur les usages, faire plus pencher la balance en défaveur qu'en faveur de l'hypothèse du renforcement de la domination, des stéréotypes ou de cadrages (Goffman, 1991) hégémoniques des rôles et capacités attribués à telle ou telle minorité. Pour reprendre I'exemple du travail de William Lhamon sur l'histoire des spectacles blackface, montrer qu'il y a une circulation historique d'un répertoire de gestes commun au prolétariat afro-américain et diasporique européen ne désamorce pas la critique classique de la contribution de cette forme culturelle à la diffusion du racisme aux États-Unis, ne

10. Pour un dépassement de l'opposition frontale entre ces deux auteurs, voir Nordmann, 2006 : 211 sqq.

11. Nous ne saurions nous permettre, avec cette publication, d'avoir la prétention sûre et certaine d'« intervenir » dans l'espace vraiment public. Mélancolique humilité qui est probablement à la fois symptôme et cause d'une crise de la fonction intellectuelle..

12. C'est le passage de l'analyse sémiologique des mythologies bourgeoises à l'ethnographie des décodages populaires des textes (voir Mattelart \& Neveu, 1996 : 31 sqq. ; Glévarec et al., 2008 : 131 sqq.). 
serait-ce qu'ailleurs que dans les théâtres populaires de New York, chez d'autres publics. La culture populaire est le lieu d'une tension entre forces (matérielles, symboliques, etc.) qui ne se résout pas systématiquement dans le triomphe de performances subversives.

\section{Les musiques populaires au service de causes politiques}

Le premier lieu observable de la politisation des musiques populaires, c'est bien sûr celui des séquences historiques à l'occasion desquelles elles s'associèrent explicitement à des causes politiques ${ }^{13}$. Il y a évidemment bon nombre d'exemples de telles mobilisations. Embrigadées dans des causes publiques, elles remplissent des fonctions et peuvent avoir des effets plus ou moins concrets, importants et durables :

- mobilisation politique générale, à l'occasion de grands mouvements sociaux et culturels, par exemple le « front culturel » américain des années 1930 (Denning, 2010) ou la contre-culture des années 1960. Cet engagement, qui implique un «travail de conflictualisation » (Traïni, 2008 : 60) - de désignation des ennemis -, peut contribuer à des transformations politiques, ponctuelles ou considérables (voir Wicke, 1992);

- association à des causes politiques spécifiques, notamment à l'occasion de manifestations, de concerts - Rock Against Racism et Red Wedge (Frith \& Street, 1992; Street, 2011), soutien à Nelson Mandela (Garofalo, 1992 : ch. iii), ou encore, dans cet ouvrage, les textes de Manabe, Podber et Snyder;

- développement d'une culture politique et d'une identité collective ancrées dans un passé de luttes, à l'aide

13. Dans la littérature académique francophone, les livres traitant exclusivement des rapports entre musiques populaires et politique sont rares. Citons les ouvrages collectifs dirigés par Alain Darré (1996), Jean-Marie Seca (2007) et quelques chapitres de celui dirigé par Justyne Balasinski et Lilian Mathieu (2006) ainsi que la courte synthèse de Christophe Traïni (2008). Pour une analyse de la musique protestataire en France, voir l'ouvrage (en anglais) de Barbara Lebrun (2009). 
PENSER LES DYNAMIQUES POLITIQUES DES MUSIQUES POPULAIRES...

d'un travail de « filiation historique » (Traïni, $2008: 27$ ), de « mobilisation des traditions » (Eyerman \& Jamison, 1998);

- fonctions de « cadrage » redéfinissant les enjeux politiques, d'agenda-setting (les chansons pacifistes des années 1960), voire de modification de l'agenda politique [agenda-building];

- dénonciation de la censure - notamment lorsqu'elle s'abat sur des œuvres ou des artistes (Cloonan \& Garofalo, 2003) -, diffusion d'informations alternatives (voir Di Nunzio \& Toscano dans cet ouvrage);

- défense de droits, parmi lesquels, bien sûr, les intérêts corporatistes (voir la contribution de Cloonan dans cet ouvrage), lobbying visant à influence ou participer à l'élaboration des politiques culturelles (voir Bennett et al., 1993; Street, 2011 : ch. ii.).

Ces fonctions et effets bénéficient éventuellement de la force de frappe de l'industrie musicale. Comme le dit John Street, " les politiques des musiques populaires se développent le mieux lorsqu'elles tentent de combiner logique commerciale et idéaux romantiques » (2001 : 244). Cette politisation n'est que rarement essentiellement le fait de forces endogènes, mais au contraire d'ajustements entre mondes musicaux, monde social et politique, attentes des fans, etc. Selon Lawrence Grossberg, le rock s'inscrivit dans le consensus idéologique dominant de son époque, et son articulation à la politique fut le fruit d'agents externes:

C'est précisément parce que le rock accepta avec tant d'innocence sa place dans le consensus libéral qu'il fut si aisément entraîné dans des luttes politiques et articulé à celles-ci, mais toujours par d'autres. (1993 : 203)

Bien évidemment, outre les cas flagrants de mobilisation par des mouvements réactionnaires ou d'extrême-droite (voir par exemple Lescop, 2003; 2012; Di Nunzio \& Toscano dans cet ouvrage), le projet politique porté par des musiques populaires peut être ambigu, se fourvoyer, que l'on pense aux nombreuses déclinaisons humanitaires des supergroups (par exemple : "We Are the World» pour 
I'Éthiopie en 1985 - voir Garofalo, 1992 : ch. i) et des méga concerts de charity rock (Live Aid, la même année, toujours pour l'Éthiopie, et vingt ans plus tard, le Live 8 autour de la dette des pays pauvres - voir Carlet et Seca, 2007). On pourrait également mentionner ce concert récent qui rassembla, en un hommage louable aux victimes des attentats de novembre 2015, un rockeur charitable mais expert en optimisation fiscale (Browning, 2007) et un autre, militant pro armes à feu et anti-avortement, supporteur enthousiaste de Ronald Reagan, George W. Bush et Donald Trump (Tronche, 2015), autour du crédo : "L'amour plus fort que la peur » (Renault, 2015). Mobilisations éphémères autour d'une cause traitée et - éventuellement - guérie superficiellement, ces types d'engagement réduisent souvent les problèmes dénoncés à un dénominateur commun, consensuel et sans adversaire tangible ( "la faim », "la misère », « la maladie »...), favorisant la dépolitisation ou la récupération politicienne.

On peut ensuite se pencher sur les discours qui ont cherché à défendre la signification et le potentiel politiques de ces musiques, à l'instar des critiques qui adoptèrent, dans le contexte brûlant de la période (mouvement des droits civiques, décolonisation, essor de la contre-culture), des concepts de l'École de Francfort ou des héritiers du marxisme (entre autres) pour penser politiquement la signification des musiques populaires. C'est le cas notamment de l'engagement des musiciens de free jazz et des écrits qui leur furent consacrés par des essayistes tels que Amiri Baraka/LeRoi Jones (2000) aux États-Unis ou de ceux, en France, de la nouvelle génération de critiques à Jazz Hot et Jazz Magazine, à l'instar du fameux ouvrage de Philippe Carles et Jean-Louis Comolli $\left(2000^{14}\right)$. De même, la manière dont, du moins en France, les militants gauchistes tentèrent de s'emparer du rock pour en faire la bande-son de l'après-68, puise dans un terreau argumentatif similaire - Adorno, Marcuse, ainsi que Barthes, Althusser, Deleuze, Debord (dénonciation du capitalisme, des mythologies bour-

14. Les analyses de Jones/Baraka inspirèrent la démarche de Carles et Comolli, qui soutinrent néanmoins qu'il fallait dépasser sa grille de lecture : ne plus simplement penser la dialectique des Noirs et des Blancs, mais celle des colons et des colonisés (Sklower, 2006 : 167-177; 2008). Sur le contexte de réception de ses écrits sur les musiques afro-américaines et les polémiques au sein du milieu intellectuel noir américain, voir Parent, 2015 : 106-119. 
geoises, de la société du spectacle, des médias, de la consommation, de la bureaucratie) - incarnation paradoxale de la « critique artiste ». Aux yeux de certains groupuscules, le rock sembla, pendant quelques années, pouvoir jouer le rôle de fédérateur des jeunes forces révolutionnaires (voir Drott, 2001 : ch. iv; Tamagne, 2012).

Dans un registre argumentatif moins dense, la critique rock chercha dans les années 1960 à légitimer l'objet de sa passion en le distinguant de la pop : une musique sérieuse, enracinée dans une grande tradition populaire (le blues, la folk) et engagée dans l'actualité contre-culturelle (Keightley, 2001). Le compagnonnage d'universitaires américains tels que Theodore Roszak (1969) et Charles Reich (1971) ou d'auteurs comme Tom Wolfe (1968) offrit à ce mouvement un apport intellectuel original (voir Whiteley, 2012; Bennett, 2012). On peut trouver des discours militants similaires dans les défenses du punk, de la techno comme du hip-hop militants.

Mais les " grands récits » qui ne valorisent ces musiques que dans la mesure où elles accompagnent des mouvements politiques légitimes, s'emparent de l'orthodoxie militante ou annoncent par leur boucan des révoltes à venir ${ }^{15}$ ont trop tendance à les réduire à une fonction instrumentale, l'engagement valant dernière chance de salut. Comprendre ce qui fait la spécificité des politiques des musiques populaires implique d'aller plus loin que le simple recensement de faits d'armes mis en musique, ou de chansons reflétant les troubles d'une époque. Car la musique peut être autre chose qu'une simple expression: une forme qui « incarne des valeurs et expériences politiques, organise notre réponse à la société comme pensée et comme action politiques » (Street, 2011 : 11). Ou pour le dire avec les mots de T. V. Reed, si elle ne peut lutter contre les

15. Le matérialisme prophétique du Bruits de Jacques Attali (2001) n'offre au lecteur que de tristes généralités sur, entre autres, le rap qui « après le free jazz, annonce l'explosion de la violence urbaine » (14) ou, plus négativement, la variété comme " production en série de tribus de consommateurs » (178), sans oublier la techno qui « se croit rébellion alors qu'elle ne fait que conférer une dimension esthétique à l'intégration à un monde répétitif » (187) (concurrençant peut-être en cela l'activité éditoriale de l'auteur...), ou encore, pêle-mêle, le « bal populaire, la rave-partie - ou leur ersatz mondain, la boîte de nuit » où la « musique n'y est qu'un masque de l'incommunicabilité, de la solitude de danseurs juxtaposés [...] interdisant de parole ceux qui, de toute façon, ne veulent ou ne peuvent pas la prendre » (197), etc. Pour une critique sérieuse de cet essai surestimé, notamment outre-Atlantique, voir Hennion (2007 : 92-94) et la dense analyse de Drott (2015). 
conditions imposées par une crise, elle permet de « donner forme à la réponse faite à ces conditions » (2005: 292). La musique n'est pas qu'un outil parmi d'autres dans un dispositif plus large de politisation, elle est elle-même déjà un dispositif et une praxis - c'est à cette échelle que nous souhaitons désormais penser cette articulation.

\section{Déviance et communalisation}

Il y a en effet une autre manière de concevoir la dynamique de politisation des musiques populaires, qui tient à leurs conditions spécifiques d'existence, et qui dépend moins de l'embrigadement par des agents politisés que de l'activité à l'œuvre dans ses pratiques. Il est intéressant de noter ici, dans la dense généalogie intellectuelle des cultural studies, d'abord l'influence du travail d'Edward P. Thompson, qui établit une histoire d'en bas des représentations de soi, des résistances (2012) et des braconnages (2015) populaires, qui envisage donc le pouvoir et ses institutions (le droit, par exemple) comme des lieux de conflictualité, et non simplement des instruments répressifs ou de monolithiques « appareils idéologiques d'État ». Parmi ces institutions traversées de conflits, il faut bien évidemment inclure les industries culturelles. On voit bien le rôle joué par l'insistance sur ces tensions au sein des institutions sociopolitiques dans l'appropriation de la conception gramscienne du pouvoir - l'hégémonie et ses transformations - au sein de ce champ (pour une synthèse sur cette question, voir par exemple Mattelart et Neveu, 1996 : 21-31). Geste qui fait également sens dans une généalogie française de son appropriation, via l'œuvre d'Edgar Morin (2008; voir aussi Macé, 2006 : 52-73) ou de Michel de Certeau (voir Maigret, 2000), par exemple.

Cet héritage - parmi d'autres - fut fructueusement mis en relation avec celui de la sociologie de l'École de Chicago, et notamment de la théorie de l'étiquetage et de la déviance. Les travaux du CCCS sur les subcultures reprirent le concept à cette école (Hall \& Jefferson, 1980 : 30-34), pour penser la manière dont les jeunes braconnent sur le terrain des industries culturelles. Plutôt que de se pencher uniquement sur les formes ostensiblement politisées de la culture 
populaire, ces analyses ont d'abord considéré les dynamiques de production d'identités socioculturelles, qui correspondent à tout un répertoire de conduites déviantes au croisement des dispositifs de pouvoir - paniques orchestrées par des entrepreneurs de morale (Cohen, 2011; Becker, 1985 : ch. vIII), institutions, lois - et des subcultures (classe, âge, plus tard race, genre, sexualité, etc.).

C'est précisément dans cette articulation entre déviance et activité populaire que l'on peut penser l'une des modalités les plus originales de la politisation des musiques populaires. Ces musiques sont à la fois produites et stigmatisées par les élites, mais cette discordance ne trouve pas sa solution unique dans la "violence symbolique ». Autour de ces musiques, auxquelles il est si facile "d'adhérer» émotionnellement et symboliquement, se forment des communautés obligées de se serrer les coudes face à cette hostilité, qui va du mépris à la censure. La reconnaissance offerte par le groupe peut bien sûr être pensée comme un simple remède - dépolitisant (Balasinski \& Mathieu, 2006 : 23) - à l'anomie ${ }^{16}$. Mais se contenter de ce pas timide hors de l'insignifiance sociale ne suffit pas. Ce déni de reconnaissance d'une culture - qui est déjà en soi un acte politique, comme nous le rappelle la citation de Theodore Gracyk en exergue de cette introduction ${ }^{17}$ - peut provoquer autre chose que le repli dans la sphère abritée de l'entre-soi :

ceux à qui I'on refuse la qualité d'être parlants et pensants revendiquent leur appartenance au monde commun et transforment le monde social par cette exigence de reconnaissance de leur égalité. (Rancière, 2009 : 169 18)

16. Pour une analyse nuancée de cette question, voir par exemple les travaux de Harris Berger sur le metal (1999).

17. Bourdieu souscrirait presque à cette idée : « les conflits proprement esthétiques sur la vision légitime du monde [...] sont des conflits politiques (suprêmement euphémisés) pour l'imposition de la définition dominante de la réalité et, en particulier, de la réalité sociale » (1977 : 29; cité in Shusterman, 1991 : 163).

18. On voit tout l'intérêt qu'il y aurait à croiser les apports des cultural studies avec la théorie de la reconnaissance d'Axel Honneth (2000), directeur actuel de l'Institut de recherche sociale de Francfort, très prisé de nos jours chez certains chercheurs en sciences de l'information et de la communication (voir par exemple Denouël \& Granjon, 2011; Granjon, 2012 - qui intègrent par ailleurs dans leurs recherches - avec des réserves - la tradition du «paradigme des usages » des dispositifs techniques, tout aussi compatible avec une perspective cultural studies) comme dans la sociologie pragmatique de la critique (voir Frère, 2015). 
Et ce d'autant plus que les critiques gagnent en véhémence, proportionnellement à la visibilité médiatique du phénomène. C'est ce que soutient Lawrence Grossberg à propos du rock, dont la « politisation fut principalement le résultat des attaques répétées qu'il suscita plutôt que de ses propres activités ou intentions » (1993: 203). Pour Alain Darré, les musiques populaires,

par la conscientisation communautaire qu'elles génèrent, peuvent apparaître comme des ferments de mobilisation sociale, des grammaires pour l'action collective. Chanteurs et musiciens sont alors les vecteurs d'une communauté qui s'imagine, se projette dans un univers social redéfini. $\left(1996: 164^{19}\right)$

L'hostilité de représentants de l'ordre social et moral vis-à-vis de ces formes culturelles peut produire des réactions plus engagées encore. Pour T. V. Reed, la politisation découle du statut même des subcultures :

Dans la mesure où, par définition, les subcultures se distinguent des cultures mainstream (le préfix sub suggérant leur statut inférieur du point de vue dominant), elles existent toujours potentiellement en tant que forces politiques.

La politisation est d'autant plus probable que ces subcultures sont perçues comme menaçantes, ajoute-t-il ensuite (2005 : 304-305).

Lorsque des scènes musicales ${ }^{20}$ ne bénéficient pas de l'appui de I'industrie et des médias ou les rejettent, leurs acteurs les plus motivés apprennent à s'organiser et à se mobiliser, pour produire, diffuser et jouir de leur musique et éventuellement en revendiquer la légitimité ${ }^{21}$. L'organisation d'une production et d'une dif-

19. Il n'y a pas là - nous nous répétons - de lien nécessaire : la même configuration peut tout à fait également contribuer à motiver des formes de repli misanthrope (certaines scènes du metal extrême), un hédonisme individualiste (gangsta rap, certaines scènes de la dance music). Mais encore une fois, nous ne pouvons pas pour autant réduire ces scènes musicales à une signification négative unique (voir, pour les trois scènes mentionnées, Berger, 1999; Bouyahia, et al., 2011; Dyer, 1979).

20. Sur ce concept, voir Guibert, 2012.

21. Dans le champ artistique légitime, la marginalisation institutionnelle et économique d'avant-gardes produit des effets similaires bien connus, selon la loi qui veut que " l'espace des positions tend[e] à commander l'espace des prises de position » (Bourdieu, 1998 : 379). Mais les sources du répertoire symbolique des musiques populaires ne peuvent être réduites à l'imitation ou à l'appropriation de modèles 
fusion alternatives au mainstream ${ }^{22}$ se fonde sur des savoir-faire qui, le cas échéant, pourront être recyclés et adaptés à un travail de politisation - de nombreuses contributions à cet ouvrage le démontrent bien. Ce que ces scènes perdent éventuellement en résonance sociale, elles le gagnent en compétences organisationnelles. II n'est d'ailleurs pas étonnant que les communautés musicales associant ségrégation sociale et/ou ethnique, stigmatisation morale et marginalisation économique fussent celles qui se politisèrent le plus radicalement, à l'instar des premiers développements du punk britannique, du rap conscient et de la techno de Détroit. En l'occurrence, registres affectifs et actions « indés » se combinent dans l'affirmation d'une dignité et la dénonciation d'une situation inique (ségrégation socioéconomique, ethnique et spatiale), éventuellement identifiée à un ennemi (tel ou tel avatar du pouvoir politique, moral ou économique).

C'est pourquoi ces phénomènes peuvent contribuer à expliquer le bon ménage des musiques populaires et des « politiques de l'identité » (voir Biddle, 2013). En tant que menace homologue vis-à-vis des normes esthétiques et morales défendues par les autorités en vigueur, il n'est pas étonnant qu'elles aient servi de catalyseur à des sociabilités et des identifications alternatives. À l'instar de la danse ou de la mode, elles permettent de styliser l'existence comme la révolte. Leur politisation se révèle une nécessité pour dénoncer l'injustice faite aux existences qu'elles symbolisent et éventuellement exiger des transformations politiques, culturelles ou légales ${ }^{23}$.

Le revers de cette hypothèse sur le potentiel politique et performatif de la situation de déviance est bien évidemment le fait que, toutes choses égales par ailleurs, au fur et à mesure qu'elles sont tolérées, reconnues, voire récupérées par la société, le marché, ou l'État et ses institutions (y compris des laboratoires de recherche en sciences sociales), la frustration du désir de reconnaissance, qui

dominants, malgré la fortune de postures provenant partiellement du champ artistique légitime (la mythologie bohème dans la folk, le rock psychédélique, le rock indépendant, l'avant-gardisme dans le free jazz ou le rock progressif, par exemple).

22. Voir par exemple les travaux de Fabien Hein sur le punk $(2011 ; 2012 a ; 2012 b)$ et, pour ce qui est de la techno, ceux de Grynszpan (1999) ou de Queudrus (2004).

23. Pour Bourdieu, même ces entreprises politiques de " restauration de l'estime de soi » impliquent « une forme de soumission aux valeurs dominantes » $(1979: 460)$. 
pouvait auparavant stimuler la communalisation et nourrir les révoltes associées, peut finir par se dissiper. C'est alors peut-être ailleurs, dans des sociétés marquées par des formes de censure politique et/ou morale plus forte que dans le monde occidental, que I'on peut repérer des dynamiques analogues de politisation (Reed, 2005 : 305) - un phénomène illustré différemment par nombre de contributions à cet ouvrage (voir Kryzhanouski, Pasternak-Mazur, Manabe, Semken). Néanmoins, tant que nos sociétés demeureront à ce point marquées par une multiplicité de situations d'exploitation et de ségrégation, ces formes culturelles continueront à servir de réservoir d'affects, d'attitudes et de symboles rétifs (voir Toscano \& Di Nunzio, Manabe, Podber et Snyder).

\section{Affects et tactiques}

Les musiques populaires font donc partie du répertoire symbolique des luttes culturelles contre I'hégémonie, et démontrent par leur organisation dans la production parfois, mais surtout dans celle des formes d'association dans les scènes musicales, les capacités d'agir qui se nichent dans la " banalité » des cultures frappées d'opprobre. En proposant d'autres « programmes de perception, d'appréciation - et souvent d'action - face au monde social » (Neveu, 1991 : 42), elles contestent les " partages du sensible » (Rancière, 2000) du misérabilisme : leurs amateurs se font un " corps voué à autre chose qu'à la domination », pour reprendre la seconde citation en exergue de cette introduction. Cette faculté communicationnelle des affects charriés par les musiques populaires est à l'œuvre de façon magistrale dans les circulations culturelles et de communalisations transnationales et transclasses (Gilroy, 2003; Lhamon, 2008).

L'activité esthétique est le premier lieu du déploiement de cette puissance. Les musiques populaires, qui utilisent avec originalité les possibilités créatives du studio, de l'amplification ou de l'informatique, qui empruntent ostentatoirement aux registres du bruyant, du grotesque, du carnavalesque, de l'exagération du stigmate (Goffman, 1975 : ch. v), ou qui manipulent, plus subrepticement, I'hybridité, le détournement, le braconnage, l'ambiguïté, l'inversion ou 
I'hypocrisie ${ }^{24}$, ne passent sous les fourches caudines de la domination qu'aux oreilles des sourds. Comme répertoire de ruses critiques, elles offrent des modèles d'action aux mouvements qui se constituent dans leur sillage. Leur tendre une oreille curieuse demande justement de faire attention à autre chose qu'à ce qui est d'ordinaire sanctionné par les sciences adaptées aux arts légitimes et leurs méthodologies - le simple fait qu'on ne puisse rendre compte de la créativité musicale populaire avec les seuls outils de la musicologie en atteste de façon éclatante.

Cette production culturelle, c'est ce que Ron Eyerman et Andrew Jamison nomment une "praxis cognitive », le rôle décisif des arts dans la « création et recréation de cadres interprétatifs au sein des mouvements sociaux » (1998: 19), qui s'incarne dans des « actions exemplaires » (ibid. : 23) et irrigue le monde social en catimini. Selon eux, les

mouvements sociaux sont des sites où émergent potentiellement des formations culturelles. Ils offrent des espaces où certains éléments de subcultures marginales peuvent devenir des forces mises au service du changement social et culturel. Les mouvements sociaux servent de médiateurs entre le marginal et le mainstream, en cristallisant et en politisant des traditions alternatives et en les dirigeant contre les blocs historiques dominants. (Ibid. : 164)

John Street ne dit pas foncièrement autre chose, lorsqu'il considère que les pratiques musicales « établissent un contexte à travers lequel la politique est vue et jugée » (2011 : 247).

Pour penser l'activité à l'œuvre dans l'organisation des musiques populaires, nous pouvons aller plus loin que ne le font Eyerman et Jamison. Avec leur concept de " praxis cognitive », ils considèrent en effet la puissance des mouvements sociaux à partir de leur capacité à produire du savoir et à le faire résonner dans des transformations culturelles. Mais pour William Roy (2010), les mouvements sociaux sont des sites où la culture est aussi un rapport social et politique, mis en scène dans toute une série d'activités de rencontre et de délibération : une praxis sociale. C'est également la position

24. Sur ces formes d'activité, voir notamment Hebdige, 2008; de Certeau, 1990; Gates, 1988; Rose, 1994; Scott, 1992 ainsi que Manabe, Podber et Snyder dans cet ouvrage. 
défendue par T. V. Reed, pour lequel l'impact des «manifestations publiques et répétées » des mouvements sociaux est redevable le plus souvent " d'actes quotidiens de préparation ordinaire et sans dimension spectaculaire [undramatic] » (2005 : xiv-xv). II faut penser la puissance politique de cette praxis à la fois cognitive, affective, somatique et sociale, ce que Sarah Thornton souligne à sa façon, avec son concept de « capital subculturel » (1995). Les exemples d'organisation alternative d'une production ou d'une diffusion mentionnés plus haut en sont une illustration. La majorité des contributions de cet ouvrage mettent également tout à fait en valeur cet aspect.

Du côté des auditeurs, comme nous l'avons déjà soutenu, la simplicité formelle et la modestie symbolique des musiques populaires en rendent le matériau socialement très malléable, un trait que vient par ailleurs confirmer la multiplicité des formes et la fréquence historique de leurs reprises (voir Saladin, 2010), quels que soient les contextes. Dans une perspective interactionniste, pourrait-on rajouter, cette malléabilité constitue un atout de la puissance performative in situ des musiques populaires : I'espace de I'interaction entre " musiqués » et « musiquants » (Rouget, 1990 : 202 sqq.) ou - pour utiliser un cadre conceptuel similaire, mais plus englobant - du « musicking » (Small, 1998) est dilaté. La résonance affective et identitaire des thèmes, la facilité de la reprise en chœur de certains airs et chants, de même que "l'investissement immédiat et enthousiaste du corps » (Shusterman, 1992: 181) grâce au rythme peuvent fluidifier l'ajustement des interactions et donc la participation et éventuellement la solidarité (voir les textes de Manabe, Podber et Snyder ${ }^{25}$ ). C'est ce que lan Biddle appelle I' « énergie affective malléable » des musiques populaires, propices à la danse comme à la révolte (2013: xiii $\left.{ }^{26}\right)$, qui est un ingrédient de toute association à un projet politique : " les formations politiques sont tout autant le produit d'une culture commune, de pratiques,

25. Cette extension de l'espace musical peut bien sûr produire des effets contraires, notamment chez ceux peu disposés à soutenir la manifestation, ou tout simplement à apprécier tel répertoire, son volume, la qualité de la retransmission sonore etc. (voir Drott, 2016, et le texte suivant).

26. Sur cette dimension somatique de l'engagement, voir le rôle de la « cinghiamattanza » dans la contribution de Di Nunzio et Toscano. 
de coutumes et de rituels qui constituent la base affective de la solidarité » (Drott, 2011 : 8). Pour Simon Frith, cette « fusion de fantaisie de l'imaginaire et de pratiques corporelles marque également I'intégration de l'esthétique et de l'éthique » (1996: 275), idée au cœur du travail de T. V. Reed (2005) sur les « actions spectaculaires» [dramatic actions] qui accompagnent les mouvements sociaux et leurs manifestations publiques.

Un ensemble d'affects, de valeurs et de mythes qui, combinés aux pratiques organisationnelles et à leurs mises en scène ritualisées, peuvent servir de terreau à l'action collective en contexte militant. C'est ce que pense Lawrence Grossberg : " l'émancipation affective » [affective empowerment] est une " condition de possibilité de l'optimisme, de la dynamisation et de la passion qui sont nécessaires à toute lutte visant à transformer le monde » (1992: 86). Des aspects que de nombreuses contributions à ce livre mettent également en valeur. Dans la seconde partie de cette introduction, où nous en présentons une synthèse, nous allons illustrer plus concrètement les richesses et les ambiguïtés des politiques des musiques populaires au $\mathrm{Xxl}^{\mathrm{e}}$ siècle. 
JEDEDIAH SKLOWER

\section{Bibliographie}

AdoRno Theodor (1986) [1953], « Une mode intemporelle. Le jazz », Prismes, Critique de la culture et de la société, trad. G. et R. RochuItz, Payot, Paris, p. 102-114.

- (1991) [1937], "Sur la musique populaire », Revue d'esthétique, no 19, p. 181-204.

- (2001) [1938], Le Caractère fétiche dans la musique et la régression de l'écoute, trad. C. David, Paris, Allia.

Adorno Theodor \& Horkheimer Max (1983) [1947], « La Production industrielle des biens culturels. Raison et mystification des masses », La Dialectique de la raison. Fragments philosophiques, Paris, Gallimard, p. 129-176.

Attal Jacques (2001) [1977], Bruits. Essai sur l'économie politique de la musique, Paris, Fayard/Presses Universitaires de France.

Balasinski Justyne \& MatHieu Lilian (eds.) (2006), Art et contestation, Rennes, Presses universitaires de Rennes.

BeCKER Howard (1985) [1963], Outsiders : études de sociologie de la déviance, Paris, Métailié.

- (1988) [1982], Les Mondes de l'art, Paris, Flammarion.

BENNETt Andy (2012), "Pour une réévaluation du concept de contreculture », Volume! La revue des musiques populaires, vol. 9, no 1, p. 19-31.

Bennett Tony, Frith Simon, Grossberg Lawrence, Shepherd John \& Turner Graeme (eds.) (1993), Rock and Popular Music. Politics, Policies, Institutions, Londres \& New York, Routledge.

Berger Harris (1999), " "Aspects du death metal". Affect, objet et vécu social de la musique », Volume! La revue des musiques populaires, vol. 5, n², p. 31-51.

BIDDLE Ian (ed.) (2013), Music and Identity Politics, Aldershot, Ashgate. BouRdieu Pierre (1977), « La production de la croyance. Contribution à une économie des biens symboliques ", Actes de la recherche en sciences sociales, $\mathrm{n}^{\circ} 13, \mathrm{p} . \mathrm{3}-43$.

- (1979), La Distinction. Critique sociale du jugement, Paris, Minuit.

- (1998), Les Règles de l'art. Genèse et structure du champ littéraire, Paris, Seuil. 
PENSER LES DYNAMIQUES POLITIQUES DES MUSIQUES POPULAIRES...

Bouyahia Malek, Freitas Franck \& Ramdani Karima (eds.) (2011), " "Sex sells, blackness too?" Stylisation des rapports de domination dans les cultures populaires et postcoloniales », Volume! La revue des musiques populaires, vol. 8, n 2 .

Browning Lynnley (2007), "The Netherlands, the New Tax Shelter Hot Spot », The New York Times, 4 février, en ligne : http://www. nytimes.com/2007/02/04/business/yourmoney/04amster.html? pagewanted $=1 \&$ ei $=5088 \&$ en $=1 \mathrm{da} 0 \mathrm{~d} 7016 \mathrm{c} 77 \mathrm{df} 26 \& \mathrm{ex}=13282$ 45200\&partner=rssnyt\&emc=rss [consulté le 17 février 2007].

Carey James (2009), Communication as Culture. Essays on Media and Society, New York \& Londres, Routledge.

CARLet Yasmine \& SeCA Jean-Marie (2007), « Vingt ans de Live Aid: le charity rock a-t-il transformé l'engagement politique en musique populaire? », in Jean-Marie Seca (ed.), Musiques populaires underground et représentations du politique, Fernelmont, InterCommunications/E.M.E., p. 41-55.

Carles Philippe \& Comolu Jean-Louis (2000) [1971], Free jazz/Black Power, Paris, Gallimard.

Cohen Stanley (2011) [1972], Folk Devils and Moral Panics, Abingdon, Routledge.

Cloonan Martin \& Garofalo Reebee (eds.) (2003), Policing Pop, Philadelphia, Temple University Press.

Cusıck Suzanne G. (2006), « Music as Torture / Music as Weapon », Trans. Revista transcultural de música, n 10, en ligne: http://www.sibetrans.com/trans/articulo/152/music-as-torturemusic-as-weapon [consulté le 20 octobre 2014].

— (2014), " "Vous êtes dans un lieu hors du monde..." : La musique dans les centres de détention de la "guerre contre la terreur" ", Transposition, n 4, en ligne : http://transposition.revues.org/490 [consulté le 20 octobre 2014].

Darré Alain (ed.) (1996), Musique et politique. Les répertoires de I'identité, Rennes, Presses universitaires de Rennes.

de Certeau Michel (1990), L'Invention du quotidien, t. 1 : Arts de faire, Paris, Gallimard.

Denning Michael (2010) [1997], The Cultural Front. The Laboring of American Culture in the Twentieth Century, New York, Verso. 
DenouëL Julie \& Granjon Fabien (eds.) (2012), Communiquer à l'ère d'internet. Regards croisés sur la sociologie des usages, Paris, Presses de l'École des Mines.

Drott Eric (2011), Music and the Elusive Revolution, Cultural Politics and Political Culture in France, 1968-1981, Berkeley, University of California Press.

- (2015), "Rereading Jacques Attali's Bruits », Critical Inquiry, vol. 41, n 4, p. 721-756.

- (2016), "Musical Contention and Contentious Music», Contemporary Music Review, en cours de publication.

DYeR Richard (1979), «In Defence of Disco », Gay Left. A Gay Socialist Journal, no 8, p. 20-23, en ligne : http://www.gayleft1970s.org/ issues/gay.left_issue.08.pdf [consulté le 10 octobre 2015].

Eyerman Ron \& Jamison Andrew (1998), Music and Social Movements : Mobilizing Tradition in the Twentieth Century, Cambridge, Cambridge University Press.

Fast Susan \& Pegley Kip (eds.) (2012), Music, Politics, and Violence, Middletown, Wesleyan University Press.

Frère Bruno (ed.) (2015), Le Tournant de la théorie critique, Paris, Desclée de Brouwer.

Frith Simon (1996), Performing Rites. Evaluating Popular Music, Oxford, Oxford University Press.

Frith Simon \& Street John (1992), "Rock Against Racism and Red Wedge : From Music to Politics, from Politics to Music », in Reebee Garofalo (ed.), Rockin' the Boat. Mass Music and Mass Movements, Boston, South End Press, p. 67-80.

Garnham Nicholas (1995), «Political Economy and Cultural Studies : Reconciliation or Divorce? », Critical Studies in Mass Communication, vol 12, n 1, p. 60-71.

Garofalo Reebee (ed.) (1992), Rockin' the Boat. Mass Music and Mass Movements, Boston, South End Press.

Gates Henry Louis (1988), The Signifying Monkey, A Theory of African-American Criticism, New York, Oxford University Press.

Gilman Lisa (2013), « Troupes hors-sol : musique, espace et mémoire dans la guerre en Irak », Volume! La revue des musiques populaires, vol. 10, no 1, p. 171-190. 
PENSER LES DYNAMIQUES POLITIQUES DES MUSIQUES POPULAIRES...

GiLroy Paul (2003) [1993], L'Atlantique noir. Modernité et double conscience, Paris, Kargo.

Glévarec Hervé, Macé Éric \& Maigret Éric (eds.) (2008), Cultural studies. Anthologie, Paris, INA/Armand Colin.

Goffman Erving (1975) [1963], Stigmate. Les usages sociaux des handicaps, Paris, Minuit.

- (1991) [1974], Les Cadres de l'expérience, Paris, Minuit.

Gracyk Theodore (2007), Listening to Popular Music : or How I learned to Stop Worrying and Love Led Zeppelin, Ann Arbor, University of Michigan Press.

Granjon Fabien (2011), Reconnaissance et usages d'internet. Une sociologie critique des pratiques de l'information connectée, Paris, Presses de l'École des Mines.

Grignon Claude \& PASSERon Jean-Claude (1989), Le Savant et le populaire. Misérabilisme et populisme en sociologie et en littérature, Paris, Seuil.

Grossberg Lawrence (1992), We Gotta Get Out of this Place. Popular Conservatisme and Postmodern Culture, Londres, Routledge.

- (1993), "The Framing of Rock: Rock and the New Conservatism », in Tony Bennett, Simon Frith, Lawrence GrossberG, John ShePherd \& Graeme Turner (eds.), Rock and Popular Music. Politics, Policies, Institutions, New York, Routledge, p. 193-209.

- (1995), «Cultural Studies vs. Political Economy : Is Anybody Else Bored with this Debate? », Critical Studies in Mass Communication, vol 12, no 1, p. 72-81.

Grynszpan Emmanuel (1999), Bruyante Techno. Réflexion sur le son de la free party, Nantes, Éd. Mélanie Seteun.

GuiberT Gérôme (2012), " La notion de scène locale. Pour une approche renouvelée des courants musicaux », in Stéphane DoriN (ed.), Sound Factory. Musique et logiques de l'industrialisation, Nantes \& Paris, Éd. Mélanie Seteun \& Uqbar, p. 93-124.

Hall Stuart (1994) [1973], "Codage/Décodage », Réseaux, n 68, trad. M. Albaret et M.-C. Gamberini, p. 27-39.

- (2007), Identités et cultures. Politiques des cultural studies, éd. Maxime Cervulle, trad. C. Jaquet, Paris, Amsterdam. 
Hall Stuart \& JefFerson Tony (eds.) (1980 [1975]), Resistance through Rituals. Youth Subcultures in Post-War Britain, Londres, Hutchinson.

HebDige Dick (2008) [1979], Sous-culture. Le sens du style, trad. M. SAINT-EXupéry, Paris, Zones.

Hein Fabien (2011), Ma Petite entreprise punk. Sociologie du système $D$, Toulouse, Kicking Box.

— (2012a), « Le DIY comme dynamique contre-culturelle? L'exemple de la scène punk rock », Volume! La revue des musiques populaires, vol. 9, n 1, p. 105-126.

- (2012b), Do it yourself! Autodétermination et culture punk, Paris, Le Passager Clandestin.

Hennion Antoine (2007), La Passion musicale. Une sociologie de la médiation, Paris, Métailié.

- (2013), « La production du succès : une anti-musicologie de la chanson de variétés ", Volume! La revue des musiques populaires, vol. 10, no 1, p. 47-73.

Honneth Axel (2000) [1992], La Lutte pour la reconnaissance, Paris, Cerf.

Johnson Bruce \& Cloonan Martin (2009), Dark Side of the Tune: Popular Music and Violence, Farnham, Ashgate.

KEIGHTLEY Keir (2001), "Reconsidering rock », in Simon FrITH, Will Straw \& John Street (eds.), The Cambridge Companion to Pop and Rock, Cambridge, Cambridge university Press, p. 109-142.

Lebrun Barbara (2009), Protest Music in France. Production, Identity and Audiences, Farnham, Ashgate.

Lescop Gildas (2003), " "Honnie soit la Oi!" Naissance, émergence et déliquescence d'une forme de protestation sociale et musicale », Volume! La revue des musiques populaires, vol. 2, $n^{\circ} 1$, p. 109-128.

— (2012), "Skinheads : du reggae au Rock Against Communism», Volume! La revue des musiques populaires, vol. 9, $n^{\circ} 1$, p. 129-149.

Lhamon William (2008) [1998], Peaux blanches, masques noirs. Performances du blackface de Jim Crow à Michael Jackson, Paris, Kargo/L'Éclat. 
Macé Éric (2006), Les Imaginaires médiatiques. Une sociologie postcritique des médias, Paris, Amsterdam.

Maigret Éric (2000), "Les trois héritages de Michel de Certeau. Un projet éclaté d'analyse de la modernité », Annales. Histoire, Sciences Sociales, vol. 55, n 3, p. 511-549.

Maigret Éric \& Macé Éric (eds.) (2005), Penser les médiacultures. Nouvelles pratiques et nouvelles approches de la représentation du monde, Paris, INAVArmand Colin.

MatTelart Armand (2011), L'Invention de la communication, Paris, La Découverte.

Mattelart Armand \& Neveu Érik (1996), «Cultural studies' stories. La domestication d'une pensée sauvage? », Réseaux, vol. 14, $n^{\circ} 80$, p. 11-58.

Morin Edgar (2008) [1962], L'Esprit du temps, Paris, INA/Armand Colin.

Neveu Érik (1991), « Won't get fooled again ? Pop musique et idéologie de la génération désabusée », in Patrick Mignon \& Antoine Hennion (eds.), Rock, de I'histoire au mythe, Paris, Anthropos, p. 41-64.

Nordman Charlotte (2006), Bourdieu/Rancière. La politique entre sociologie et philosophie, Paris, Amsterdam.

Parent Emmanuel (2015), Jazz power. Anthropologie de la condition noire chez Ralph Ellison, Paris, CNRS.

PiesLak Jonathan (2009), Sound Targets, Bloomington \& Indianapolis, Indiana University Press.

Queudrus Sandy (2004), Un Maquis techno. Modes d'engagement et pratiques sociales dans la free party, Nantes, Éd. Mélanie Seteun.

Rancière Jacques (2000), Le Partage du sensible. Esthétique et politique, Paris, La Fabrique.

- (2009), Le Spectateur émancipé, Paris, la Fabrique.

Reed Thomas V. (2005), The Art of Protest. Culture and Activism from the Civil Rights Movement to the Streets of Seattle, Minneapolis, University of Minnesota Press.

Reich Charles A. (1971), The Greening of America, Middlesex, Allen Lane. 
EDEDIAH SKLOWER

Renault Gilles (2015), "Avec U2, les Eagles of Death Metal remontent sur scène à Paris », Libération, en ligne : http://next. liberation.fr/culture-next/2015/12/08/avec-u2-les-eagles-ofdeath-metal-remontent-sur-scene-a-paris_1419092 [consulté le 9 décembre 2015].

RIoux Jean-Pierre \& SIRINELLI Jean-François (2005) [1998], Histoire culturelle de la France, t. 4 : Le Temps des masses. Le vingtième siècle, Paris, Seuil.

Rose Tricia (1994), Black Noise. Rap Music and Black Culture in Contemporary America, Middletown, Wesleyan University Press.

Roszak Theodore (1969), The Making of a Counter Culture: Reflections on the Technocratic Society and its Youthful Opposition, Londres, Faber and Faber.

Rouget Gilbert (1990) [1980], La Musique et la transe, Paris, Gallimard.

Roy William G. (2010), Reds, Whites, and Blues : Social Movements, Folk Music, and Race in the United States, Princeton, Princeton University Press.

Rudy Dario \& CITton Yves (2014), « Le lo-fi : épaissir la médiation pour intensifier la relation », Écologie et politique, n 48, p. 109-124.

Saladin Matthieu (ed.) (2012), "La reprise » et "La reprise bis", Volume! La revue des musiques populaires, vol. 7, n 1 \& 2

SECA Jean-Marie (ed.) (2007), Musiques populaires underground et représentations du politique, Fernelmont, InterCommunications/ E.M.E.

Scott Derek (2008), Sounds of the Metropolis. The NineteenthCentury Popular Music Revolution in London, New York, Paris, and Vienna, Oxford, Oxford University Press.

Scott James C. (1992), Domination and the Arts of Resistance. Hidden Transcripts, New Haven \& Londres, Yale University Press.

Shusterman Richard (1992), L'Art à l'état vif. La pensée pragmatiste et l'esthétique populaire, Paris, Minuit.

SkLOWER Jedediah (2006), Free jazz, la catastrophe féconde. Une histoire du monde éclaté du jazz en France (1960-1982), Paris, L'Harmattan. 
PENSER LES DYNAMIQUES POLITIQUES DES MUSIQUES POPULAIRES...

- (2008), «Rebel with the wrong cause. Albert Ayler et la signification du free jazz en France (1959-1971) », Volume! La revue des musiques populaires, n 6, vol. 1 \& 2, p. 193-219.

Small Christopher (1998), Musicking. The Meanings of Performing and Listening, Middletown, Wesleyan University Press.

Street John (2001), "Rock, pop and politics », in Simon Frith, Will Straw \& John Street (eds.), The Cambridge Companion to Pop and Rock, Cambridge, Cambridge University Press, p. 243-255.

- (2011), Music \& Politics, Cambridge, Polity.

TAGg Philip (1982), « Analysing Popular Music: Theory, method and practice », Popular Music, n², p. 37-65.

TAMAGnE Florence (2012), "L'interdiction des festivals pop au début des années 1970 : une comparaison franco-britannique », Territoires Contemporains, nouvelle série, $\mathrm{n}^{\circ} 3$, en ligne : http:// tristan.u-bourgogne.fr/CGC/publications/Festivals_societes/F_ Tamagne.html [consulté le 10 septembre 2015].

Thompson Edward P. (2012), La Formation de la classe ouvrière anglaise, Paris, Seuil.

- (2015), Les Usages de la coutume. Traditions et résistances populaires en Angleterre, XVII -XIXe siècles, Paris, EHESS/Gallimard/Seuil.

Thornton Sarah (1995), Club Cultures: Music, Media, and Subcultural Capital, Cambridge, Polity Press.

Traînı Christophe (2008), La Musique en colère, Paris, Presses de Sciences Po.

Tronche Jean-Frédéric (2015), " Jesse Hugues, leader des Eagles of death metal, ses flingues, sa paroisse ", L'Obs, 3 décembre, en ligne: http://tempsreel.nouvelobs.com/attentats-terroristes-a-paris/20151203.OBS0707/jesse-hugues-leader-deseagles-of-death-metal-ses-flingues-sa-paroisse.html [consulté le 9 décembre 2015].

VolCler Juliette (2011), Le Son comme arme. Les usages policiers et militaires du son, Paris, La Découverte.

Whiteley Sheila (ed.) (2012), "Contre-cultures », vol. 1 : « Musiques, théorie et scènes » et vol. 2 : "Utopies, dystopies, anarchie », Volume! La revue des musiques populaires, vol. 9, nº $1 \& 2$. 
JEDEDIAH SKLOWER

Wicke Peter (1992), "The Times They Are A-Changin' : Rock Music and Political Change in East Germany », in Reebee Garofalo (ed.), Rockin' the Boat. Mass Music and Mass Movements, Boston, South End Press, p. 81-92.

Wolfe Tom (1968), The Electric Kool-Aid Acid Test, New York, Farrar, Straus and Giroux. 